\title{
Three-dimensional Analysis of Rainfall-induced Slope Failure
}

\author{
Ram K. REGMI ${ }^{1}$, Hajime NAKAGAWA ${ }^{2}$, Kenji KAWAIKE ${ }^{2}$, \\ Yasuyuki BABA ${ }^{3}$ and Hao $\mathrm{ZHANG}^{2}$ \\ ${ }^{1}$ Dept. of Civil and Earth Resources Engineering, Kyoto University (Shimomisu, Fushimi, Kyoto 612-8235, Japan) \\ E-mail: rkregmi@engineer.com \\ 2 Disaster Prevention Research Institute, Kyoto University (Shimomisu, Fushimi, Kyoto 612-8235, Japan) \\ 3 Disaster Prevention Research Institute, Kyoto University (Shirahama, Muro-gun, Wakayama 649-2201, Japan)
}

\begin{abstract}
Numerical simulations and flume experiments were performed to investigate the mechanism of slope failure due to rainfall events. A three-dimensional (3D) seepage flow numerical simulation model was coupled with a two-dimensional (2D) surface flow and erosion/deposition model for the seepage analysis. The conventional water-phase (one-phase) seepage-flow model assumed only water-phase flow in the seepage analysis, which was inadequate for unsaturated soil domains. A water-air two-phase seepage-flow model that considered both the water and air phases in the seepage-flow process was also used for the seepage analysis. The pore-water pressure and moisture-content data obtained from the seepage-flow model were used to analyze the slope stability. Janbu's simplified method and the extended Spencer method were used for the stability analysis. The numerical simulation and experimental measurements agreed satisfactorily in terms of moisture and air movement, seepage outflow rate, surface water forefront propagation, predicted critical slip surfaces, and time of failure of the considered slope.
\end{abstract}

Key words: numerical simulation, two-phase seepage-flow, slope failure, critical slip surface

\section{INTRODUCTION}

In general, rainfall-induced slope failures are caused by increased pore pressure and seepage force during periods of intense rainfall. The effective stress in the soil decreases due to the increased pore pressure, reducing the soil shear strength, and ultimately resulting in slope failure. During rainfall, a wetting front moves downward into the slope, resulting in a gradual increase in water content and decrease in negative pore-water pressure. This negative pore-water pressure is referred to as matric suction when referencing the pore-air pressure that contributes to unsaturated-soil slope stability.

Various physical models coupling infinite slope-stability analyses with hydrological modeling have been developed assuming a steady or quasi-steady water table and groundwater flow parallel to the hill slope. Tsai et al. [2008] developed a physical model using the complete Richards' equation with the effect of the slope angle and also adopted the extended Mohr-Coulomb failure criterion [Fredlund et al., 1978] to describe the unsaturated shear strength.

Sassa [1972, 1974] conducted a series of flume tests and concluded that the changes in rigidity of sand and the upper yield strain within a slope were essential to slope-stability analyses. Fukuzono [1987] conducted an experiment to examine the conditions leading to slope failure using near-actual-scale slope models providing heavy rainfall. Crozier [1999] tested a rainfall-based landslide-triggering model developed from landslide episodes in Wellington, New Zealand, termed the Antecedent Water Status Model, to predict landslide occurrence by providing a 24-h forecast. Tsutsumi and Fujita [2008] investigated several landslide sites and used physical experiments and numerical simulations with a combination of rainwater infiltration for their slope-stability analysis. Mukhlisin and Taha [2009] developed a numerical model to estimate the extent of rainwater infiltration into an unsaturated slope, the formation of a saturated zone, and the change in slope stability. Then, the model was used to analyze the effects of soil thickness on the occurrence of slope failure.

These numerical studies are applicable only to 
two-dimensional (2D) analyses, whereas slope failure occurs in three dimensions. Furthermore, soil slopes have both water and air phases. Although pore air and water both influence seepage flow, all of the above-mentioned studies neglected airflow in their seepage analyses. In examining the behavior of unsaturated soils, authors such as Dakshanamurthy et al. [1984] incorporated the airflow within the soil, proving it to be significant to the overall soil behavior. Therefore, a numerical study in three dimensions is necessary for seepage and slope stability analyses that consider the effects of the air phase in the seepage.

This study analyzed slope failure due to rainfall using the pore-water pressure and moisture content calculated with a conventional water-phase seepage-flow model and a water-air two-phase seepage-flow model. Janbu's simplified method and the extended Spencer method were incorporated into dynamic programming to locate the critical slip surface of a general slope. The simulation results were compared with experimental results to evaluate the model.

\section{NUMERICAL MODELING}

\subsection{Seepage flow model}

The pressure-based Richards' equation (Eq. (1)), valid for variably saturated soil, was used in a conventional three-dimensional (3D) seepage-flow model to calculate the change in pore-water pressure inside the model slope [Awal et al., 2009].

$$
\begin{gathered}
\left(C+S_{w} S_{s}\right) \frac{\partial h_{w}}{\partial t}=\frac{\partial}{\partial x}\left(K_{w x} \frac{\partial h_{w}}{\partial x}\right)+ \\
\frac{\partial}{\partial y}\left(K_{w y} \frac{\partial h_{w}}{\partial y}\right)+\frac{\partial}{\partial z}\left(K_{w z}\left(\frac{\partial h_{w}}{\partial z}+1\right)\right)
\end{gathered},
$$

where $h_{w}$ is the water pressure head; $K_{w x}, K_{w y}$, and $K_{w z}$ are the hydraulic conductivity in the $x, y$, and $z$ directions, respectively; $C=\partial \theta_{w} / \partial h_{w}$ is the specific moisture capacity; $\theta_{w}$ is the soil volumetric water content; $S_{w}$ is the saturation ratio $\left(=\theta_{w} / n\right) ; S_{s}$ is the specific storage; $t$ is the time; $x$ and $y$ are the horizontal spatial coordinates; and $z$ is the vertical spatial coordinate taken as positive upwards. $S_{s}$ depends on the compressibility of the solid matrix and fluid, so it approaches zero in an unsaturated, unconfined porous medium.

To solve Eq. (1), the following constitutive relationships proposed by van Genuchten [1980] were used to establish the relationship of $\theta_{w}-h_{w}$ and $K_{w}-\theta_{w}$ :

$$
S_{e}=\left[1+\left(\left|\alpha h_{w}\right|\right)^{\eta}\right]^{-m}
$$

$$
\begin{gathered}
S_{e}=\frac{\theta_{w}-\theta_{r}}{\theta_{s}-\theta_{r}} \\
C=\frac{\left(n-\theta_{r}\right) \eta m \alpha\left|\alpha h_{w}\right|^{\eta-1}}{\left(1+\left|\alpha h_{w}\right|^{\eta}\right)^{m+1}} \\
K_{w}=K_{w s} S_{e}^{0.5}\left[1-\left(1-S_{e}{ }^{1 / m}\right)^{m}\right]^{2},
\end{gathered}
$$

where $S_{e}$ is the effective saturation; $\alpha$ and $\eta$ are empirical parameters; $\theta_{s}$ and $\theta_{r}$ are the saturated and residual moisture contents, respectively; $n$ is the soil porosity; $K_{w s}$ is the saturated hydraulic conductivity; and $m=1-1 / \eta$.

To analyze 3D water-air two-phase seepage flow, the following equations were derived for the simultaneous flow of water and air based on one-dimensional (1D) flow equations [Touma and Vauclin, 1986].

Water-phase equation:

$$
\begin{aligned}
& C\left(\frac{\partial h_{a}}{\partial t}-\frac{\partial h_{w}}{\partial t}\right)=\frac{\partial}{\partial x}\left(K_{w x} \frac{\partial h_{w}}{\partial x}\right)+ \\
& \frac{\partial}{\partial y}\left(K_{w y} \frac{\partial h_{w}}{\partial y}\right)+\frac{\partial}{\partial z}\left(K_{w z}\left(\frac{\partial h_{w}}{\partial z}+1\right)\right)
\end{aligned}
$$

Air-phase equation:

$$
\begin{aligned}
& \left(\left(n-\theta_{w}\right) \frac{\rho_{o a}}{h_{o}}-\rho_{a} C\right) \frac{\partial h_{a}}{\partial t}+\rho_{a} C \frac{\partial h_{w}}{\partial t}= \\
& \frac{\partial}{\partial x}\left(\rho_{a} K_{a x} \frac{\partial h_{a}}{\partial x}\right)+\frac{\partial}{\partial y}\left(\rho_{a} K_{a y} \frac{\partial h_{a}}{\partial y}\right)+, \\
& \frac{\partial}{\partial z}\left(\rho_{a} K_{a z}\left(\frac{\partial h_{a}}{\partial z}+\frac{\rho_{a}}{\rho_{o w}}\right)\right)
\end{aligned}
$$

where $h_{a}$ is the air-pressure head; $h_{o}$ is the atmospheric pressure expressed in terms of the water-column height; $C=\partial \theta_{w} / \partial h_{c}$ is the specific moisture capacity; $h_{c}=h_{a}-h_{w}$ is the capillary head; $n$ is the soil porosity; $\rho_{a}$ is the density of air; $\rho_{o a}$ is the density of air at atmospheric pressure; $\rho_{\text {ow }}$ is the density of water at atmospheric pressure; and $K_{a x}$, $K_{a y}$, and $K_{a z}$ are the air conductivity in the $x, y$, and $z$ directions, respectively.

To solve Eqs. (6) and (7), the following constitutive relationships proposed by van Genuchten [1980] were used:

$$
\begin{gathered}
S_{e}=\left[1+\left(\alpha h_{c}\right)^{\eta}\right]^{-m} \\
S_{e}=\frac{\theta_{w}-\theta_{r}}{\theta_{s}-\theta_{r}} \\
C=-\frac{\left(n-\theta_{r}\right) \eta m \alpha\left(\alpha h_{c}\right)^{\eta-1}}{\left(1+\left(\alpha h_{c}\right)^{\eta}\right)^{m+1}} .
\end{gathered}
$$

Chen et al. [1999] used the following relationships as the van Genuchten and Mualem (VGM) model: 


$$
\begin{gathered}
K_{w}=K_{w s} S_{e}^{0.5}\left[1-\left(1-S_{e}^{1 / m}\right)^{m}\right]^{2} \\
K_{a}=K_{a s} S_{e}^{0.5}\left(1-S_{e}\right)^{0.5}\left[\left(1-S_{e}^{1 / m}\right)\right]^{2 m},
\end{gathered}
$$

where $K_{a s}=K_{w s} \times\left(\mu_{w} / \mu_{a}\right)$ is the saturated air conductivity, and $\mu_{w}$ and $\mu_{a}$ are the dynamic viscosity of water and air, respectively. Additionally, $\mu_{w}=1.002 \times 10-2 \mathrm{NS} / \mathrm{m}^{2}$ and $\mu_{a}=1.83$ $\times 10-5 \mathrm{NS} / \mathrm{m}^{2}$ at $20^{\circ} \mathrm{C}$.

Then, Eqs. (1), (6), and (7) were solved using a line-successive over-relaxation (LSOR) scheme with an implicit iterative finite-difference scheme as used by Freeze [1978]. Although the implicit scheme is unconditionally stable, some difficulty due to the strong nonlinearity of these equations can occur, which can be overcome using the adaptable time step. However, this model used a very small time step of 0.01 second.

The top surface boundary was set as the constant head or constant flux due to a rainfall event in the equation for the water phase. By contrast, in the equation for the air phase, no air flow at the surface or variable air-pressure head was allowed. The downstream boundary condition was modeled as a seepage face with zero pressure head, and the upstream, left, and right boundaries were considered as no-flow boundaries for both the water- and air-phase equations. The values of the moisture content (0.006) and air-pressure head $(0.0 \mathrm{~m})$ throughout the soil domain were specified as initial conditions.

\subsection{Surface-flow and erosion/deposition model}

The mathematical model developed by Takahashi and Nakagawa [1994] was used to investigate the surface flow and erosion/deposition on the surface of the model slope. The depth-wise averaged 2D momentum equations for the $\mathrm{x}$-wise (down valley) and y-wise (lateral) directions are

$$
\begin{aligned}
& \frac{\partial M}{\partial t}+\beta \frac{\partial(u M)}{\partial x}+\beta \frac{\partial(v M)}{\partial y}= \\
& g h \sin \theta_{b x o}-g h \cos \theta_{b x o} \frac{\partial\left(h+z_{b}\right)}{\partial x}-\frac{\tau_{b x}}{\rho_{T}}
\end{aligned}
$$

and

$$
\begin{aligned}
& \frac{\partial N}{\partial t}+\beta \frac{\partial(u N)}{\partial x}+\beta \frac{\partial(v N)}{\partial y}= \\
& g h \sin \theta_{b y o}-g h \cos \theta_{b y o} \frac{\partial\left(h+z_{b}\right)}{\partial y}-\frac{\tau_{b y}}{\rho_{T}}
\end{aligned}
$$

The continuity equation of the total volume is

$$
\frac{\partial h}{\partial t}+\frac{\partial M}{\partial x}+\frac{\partial N}{\partial y}=i_{b}\left\{c_{*}+\left(1-c_{*}\right) s_{b}\right\}+R-I
$$

The continuity equation of the particle fraction is

$$
\frac{\partial(c h)}{\partial t}+\frac{\partial(c M)}{\partial x}+\frac{\partial(c N)}{\partial y}=i_{b} c_{*}
$$

The equation for the change in bed-surface elevation is:

$$
\frac{\partial z_{b}}{\partial t}=-i_{b}
$$

where $M(=u h)$ and $N(=v h)$ are the flow discharge per unit width in the $x$ and $y$ directions; $u$ and $v$ are the depth-averaged velocities in the $x$ and $y$ directions, respectively; $h$ is the water depth; $g$ is the gravitational acceleration; $\beta$ is the momentum correction factor; $\rho_{T}$ is the mixture density; $\tau_{b x}$ and $\tau_{b y}$ are the bottom shear stresses in the $x$ and $y$ directions, respectively, obtained from the expressions in Takahashi [1991]; $s_{b}$ is the degree of saturation in the bed; $R$ is the rainfall intensity; $I$ is the infiltration rate; $i_{b}$ is the rate of hydraulic erosion or deposition from the flowing water; $c$ is the sediment concentration in the flow; $c *$ is the maximum sediment concentration in the bed; and $z_{b}$ is the erosion or deposition thickness measured from the original bed elevation. Using the following relationships, $s_{b}$ and $I$ were obtained through seepage analysis: $s_{b}=\theta_{w} / \theta_{s}$ for the top cell. If $h>0$, then $I=K_{w s}\left(\partial h_{w} / \partial z+1\right)$ of the top cell; otherwise, $I$ $=R$.

The erosion and deposition velocities given by Takahashi [1991] are expressed in Eqs. (18) and (19), respectively.

$$
\begin{gathered}
\frac{i_{b}}{\sqrt{g h}}=K_{e} \sin ^{3 / 2} \theta_{b}\left\{1-\frac{\sigma-\rho_{T}}{\rho_{T}} c\left(\frac{\tan \phi}{\tan \theta}-1\right)\right\}^{1 / 2} \\
\left(\frac{\tan \phi}{\tan \theta}-1\right)\left(c_{\infty}-c\right) \frac{h}{d_{m}} \\
i_{b}=\delta_{d} \frac{c_{\infty}-c}{c_{*}} \sqrt{u^{2}+v^{2}}
\end{gathered}
$$

where $K_{e}$ is the erosion velocity parameter; $\theta_{b}$ is the bed slope; $\sigma$ is the density of the sediment particles; $\varnothing$ is the internal friction angle of the bed; $\tan \theta$ is the gradient of the energy slope; $d_{m}$ is the mean particle size; $c_{\infty}$ is the equilibrium solids concentration, obtained from the expressions given by Nakagawa et al. [2003]; and $\delta_{d}$ is a constant.

The finite-difference forms of Eqs. (13)-(16) were obtained using the solution methods developed by Nakagawa [1989] using the leap-frog scheme, in which an upwind scheme was adopted in the advection term, and an implicit scheme was introduced in the friction term. As a boundary condition, the downstream boundary was modeled as the outflow boundary, and the upstream, left, and right boundaries were considered as no-flow 
boundaries. The flow in the channel was assumed to be dry as an initial condition.

\subsection{Slope stability model}

The limit equilibrium method of slices was used for the slope-stability analysis. Janbu's simplified method and the extended Spencer method were incorporated into an effective minimization procedure based on dynamic programming, in which the minimum safety factor and corresponding critical non-circular slip surface were determined simultaneously.

Awal et al. [2009] used the following expression of Janbu's simplified method to determine the safety factor Fs.

$$
F_{s}=\frac{\sum\left[\frac{\left(c_{e}-u_{p} \tan \phi\right) \Delta x \Delta y+(W+P) \tan \phi}{\left(1 / J+\sin \alpha_{x z} \tan \phi F_{S}\right) \cos \alpha_{x z}}\right]}{\sum(W+P) \tan \alpha_{x z}}
$$

where $J=\left(1+\tan ^{2} \alpha_{x z}+\tan ^{2} \alpha_{y z}\right)^{1 / 2} ; W$ is the weight of a column; $P$ is the vertical external force acting on the top of the column; $u_{p}$ is the pore water pressure at the base of the column; $\Delta x$ and $\Delta y$ are the discretized column widths in the $x$ and $y$ directions, respectively; $\alpha_{x z}$ and $\alpha_{y z}$ are the inclination angles of the column base to the horizontal direction in the $x z$ and $y z$ planes, respectively; and $c_{e}$ and $\phi$ are the Mohr-Coulomb strength parameters.

The following equations for the safety factors for the extended Spencer method were used [Jiang and Yamagami, 2004].

$$
\begin{aligned}
F_{f}= & \left.\frac{\sum\left[\begin{array}{l}
\left(c_{e}-u_{p} \tan \phi\right) \sec \alpha_{x z} \Delta x \Delta y+(W+P) \\
\left(\sec \alpha_{x z}-\tan \delta \sin \alpha_{x z}\right) \tan \phi+ \\
F_{f} \tan \delta \tan ^{2} \alpha_{x z} / J
\end{array}\right]}{\sum(W+P) \tan \alpha_{x z}}\right] m_{\alpha} \\
F_{m}= & \frac{\sum D\left[\begin{array}{l}
\left(c_{e}-u_{p} \tan \phi\right) \sec \alpha_{x z} \Delta x \Delta y \sin \left(\theta_{d}+\delta\right) / \\
\cos \delta+(W+P) \cos \left(\theta_{d}+\alpha_{x z}\right) \\
\left\{\tan \phi \tan \left(\theta_{d}+\alpha_{x z}\right)+F_{m} \sec \alpha_{x z} / J\right\}
\end{array}\right]}{\sum(W+P) D \cos \theta_{d}},
\end{aligned}
$$

where $F_{f}$ and $F_{m}$ are the safety factors with respect to the force and moment equilibria, respectively; $m_{\alpha}$ $=\left(1+\tan \delta \tan \alpha_{x z}\right) / J+\left(\sin \alpha_{x z}-\tan \delta \cos \alpha_{x z}\right)$ $\tan \phi / F$, with $F=F_{f}$ for Eq. (21) and $F_{m}$ for Eq. (22); $\delta$ is the inclination of the interslice forces to the horizontal; $D$ is the distance from the axis of rotation to the base center of a column in the $x z$ plane; and $\theta_{d}$ is the angle between the horizontal direction and the $D$ direction in the $x-z$ plane.

$F_{f}$ and $F_{m}$ can be computed separately from Eqs. (21) and (22) for several appropriate values of $\delta$.
Then, two curves showing the relationships of $F_{f}-\delta$ and $F_{m}-\delta$ can be plotted so that the intersection of these two curves leads to a required $\delta_{o}$ value and corresponding safety factor $F_{s}$, satisfying both the force and moment equilibria.

\section{EXPERIMENTAL STUDY}

A 3-m-long, 80-cm-wide, 70-cm-deep rectangular flume with an adjustable longitudinal slope was used for the experiment. The flume sidewalls were made of aquarium glass. Three digital video cameras (VCs) were used to capture the initiation of the slope failure process and movement of the failure mass. Two cameras were placed on the sides and one in front of the flume. The experiments were conducted on $23^{\circ}$ and $28^{\circ}$ flume slopes.

It is difficult to observe a 3D view of the failure surface in a rectangular flume. Consequently, the rectangular shape of the flume was modified using wooden plates $292.5 \mathrm{~cm}$ long $\times 3 \mathrm{~cm}$ thick to make a V-shaped valley cross section with a $20^{\circ}$ cross slope. Slope failures can be rapid and devastating on steep slopes and imperceptibly slow in gentle slopes. Therefore, a comparatively steeper slope was provided in the sloping face of the model slope, and in the down-slope direction, the thickness was tapered. The model slope was prepared on a rigid flume bed with medium-grained silica sand S6.

A small space was provided upstream of runoff input to develop a water table in the bottom layer of the model slope, which is essential for understanding slope failure. The downstream end of the flume was closed with a filter mat supported by a wooden plate to retain the soil and provide free flow conditions downstream. The downstream seepage outflow was collected in a measuring cylinder via a metal container. Profile probes (PRs) consisting of four sensors (SRs) were used to measure the temporal variation in the moisture content, and pressure transducers (PTs) were used to measure the temporal variation in the air pressure at different locations inside the body of the model slope. Red sediment strips and red cotton threads were placed at the sidewall faces and inside the body, normal to the flume bed, respectively, to measure the failure surface after sliding. Measuring scales were placed vertically on the top surface of the model slope in the central longitudinal section to measure the forefront of the propagated surface water flow. The shape and size of the model slope with the arrangement of SRs, PTs, and surface-water measurement scales are shown in Figs. 1 and 2. Some parameter values of the 
sediment used in the experiments are listed in Table 1.

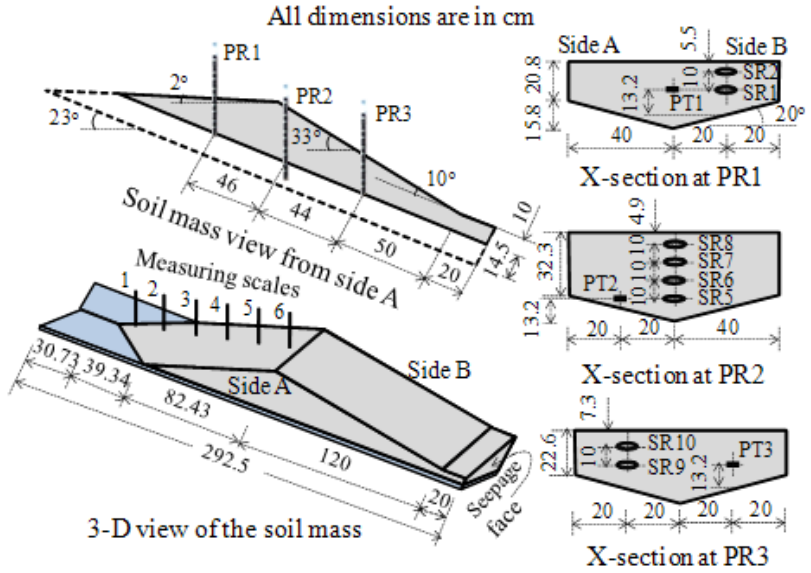

Fig. 1 The model slope with the arrangement of SRs, PTs, and surface-water forefront measurement scales (Flume slope $23^{\circ}$ )

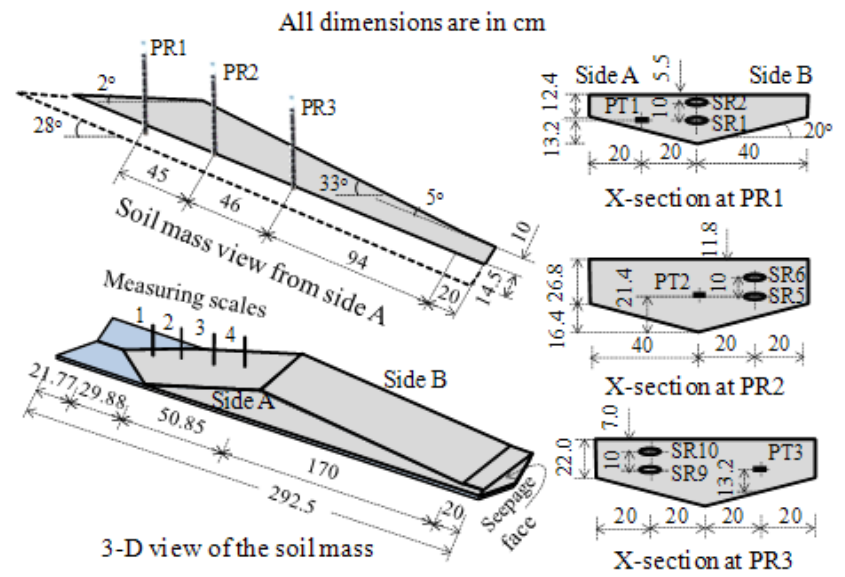

Fig. 2 The model slope with the arrangement of SRs, PTs, and surface-water forefront measurement scales (Flume slope $28^{\circ}$ )

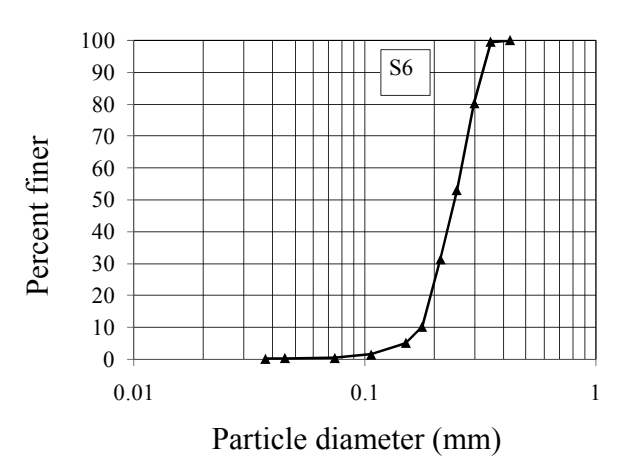

Fig. 3 Grain size distribution of the sediment (mm)

Table 1 Some parameter values of the sediment considered

\begin{tabular}{clc}
\hline Sediment type & S6 \\
\hline Saturated moisture content, & $\theta_{s}$ & 0.42 \\
Residual moisture content, & $\theta_{r}$ & 0.004 \\
van Genuchten parameter, $\quad \alpha$ & 3.227 \\
van Genuchten parameter, $\quad \eta$ & 2.7 \\
Specific gravity, $\quad G_{s}$ & 2.63 \\
Mean grain size, $\mathrm{D}_{50}(\mathrm{~mm})$ & 0.24 \\
Angle of repose, $\quad \varnothing$ & $34^{\circ}$ \\
Porosity, $\quad n$ & 0.42 \\
Compression index, $C I$ & 1.08 \\
\hline
\end{tabular}

The grain-size distributions of the sediment are shown in Fig. 3.

The artificial rainfall over the flume, provided by the simulators, was non-uniform. Additionally, the measured rainfall values at the same location differed among measurements. This unreliability in rainfall-intensity was due to power fluctuations in the water pump, losses in the water-supply pipes, and temperature variation. To measure the rainfall intensity, five experiments were conducted at 98 $\mathrm{L} / \mathrm{min}$ in different seasons throughout the year. The average value of these measurements was 105.03 $\mathrm{mm} / \mathrm{hr}$, which was assumed as the supply rainfall value in the experiments and simulations. Fig. 4 is a contour map showing the rainfall distribution over the flume.

\section{RESULTS AND DISCUSSIONS}

In the seepage-flow model, the numerical simulation was conducted at 0.01 -sec time steps and $2.5-\mathrm{cm}$ space steps in the $x$ (longitudinal), $y$ (lateral), and $z$ (vertical) directions. The $x$ and $y$ directions were assumed to be horizontal. In the surface-water flow and erosion/deposition models, 0.005 -sec time steps and $2.5-\mathrm{cm}$ space steps in the $x$ (parallel to longitudinal axis of flume) and $y$ (horizontal) directions were used. Time steps of $10 \mathrm{sec}$ and space steps of $10 \mathrm{~cm}$ in the horizontal $x$ and $y$ directions were used in the slope-stability model.

The parameters of the numerical simulation were: $K_{w x}=K_{w y}=K_{w z}=K_{w}, K_{a x}=K_{a y}=K_{a z}=K_{a}, K_{w s}$ $=0.0002153 \mathrm{~m} / \mathrm{sec} ; h_{o}=10.336 \mathrm{~m} ; g=9.81 \mathrm{~m} / \mathrm{sec}^{2}$; $\rho_{T}=\rho_{\text {ow }}=1000.0 \mathrm{~kg} / \mathrm{m}^{3} ; \rho_{\text {oa }}=1.275 \mathrm{~kg} / \mathrm{m}^{3} ; \beta=$ $1.25 ; c_{*}=0.5779 ; K_{e}=0.06 ; \sigma=2630 \mathrm{~kg} / \mathrm{m}^{3} ; \delta_{d}=$ 0.03 ; and $S_{s}=1 \times 10^{-7} \mathrm{~m}^{-1}$ (for the saturated condition of the sediment).

The electromagnetic field of the profile probe sensors extended up to $60 \mathrm{~mm}$ into the soil. The 
influence of SR8 and SR10 for the $23^{\circ}$ flume slope and of SR6 and SR10 for the $28^{\circ}$ flume slope reached the soil surface in the sloping face of the model slope (Figs. 1 and 2). The moisture profiles in the experiments and simulations did not match well for these sensors (Figs. 5 and 6). However, the profiles of the other sensors were in good agreement.

Air became trapped in the sediment voids by the water infiltrating from the surface, initially compressing the air phase and reducing the rate of water infiltration. The air pressure increased until it was sufficient for the air to escape via bubbling. The moisture profiles obtained from the two-phase flow were delayed slightly compared with those for the one-phase flow (Figs. 5 and 6). Additionally, the air-pressure-head profiles at different PTs obtained from the simulations and experiments were in good agreement (Fig. 7). The experimental and simulated seepage outflows from the downstream seepage face are shown in Fig. 8. Table 2 compares the experimental and simulated surface-water forefront propagation time at different measurement scales. These simulation results agreed well with the experimental data.

The effect of unreliable rainfall supply is evident in the comparison of the experimental and simulation results. For the $23^{\circ}$ flume slope, full saturation of the moisture profiles was delayed in the simulations compared with the experiments for almost all of the sensors (Fig. 5). Additionally, the air-pressure-head profiles (Fig. 7) and surface-water forefront propagation (Table 2) were delayed in the simulations. These results indicated greater rainfall intensity in the experiments than the average simulated rainfall.

For the $28^{\circ}$ flume slope, most of the sensors indicated that full saturation of the moisture profiles occurred earlier in the simulations than the experiments showed (Fig. 6). The air-pressure-head profiles, except PT3 (Fig. 7), and surface-water forefront propagation (Table 2) were faster in the simulations. These results indicated that the rainfall intensity in the experiments was less than the
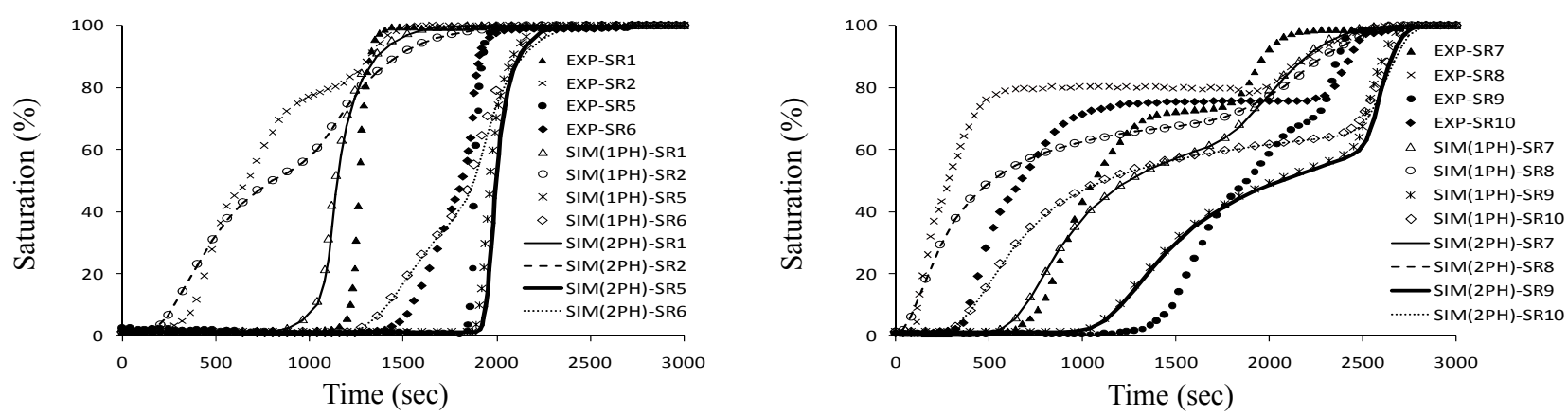

Fig. 5 Simulated and experimental moisture content profiles ( $23^{\circ}$ flume slope)
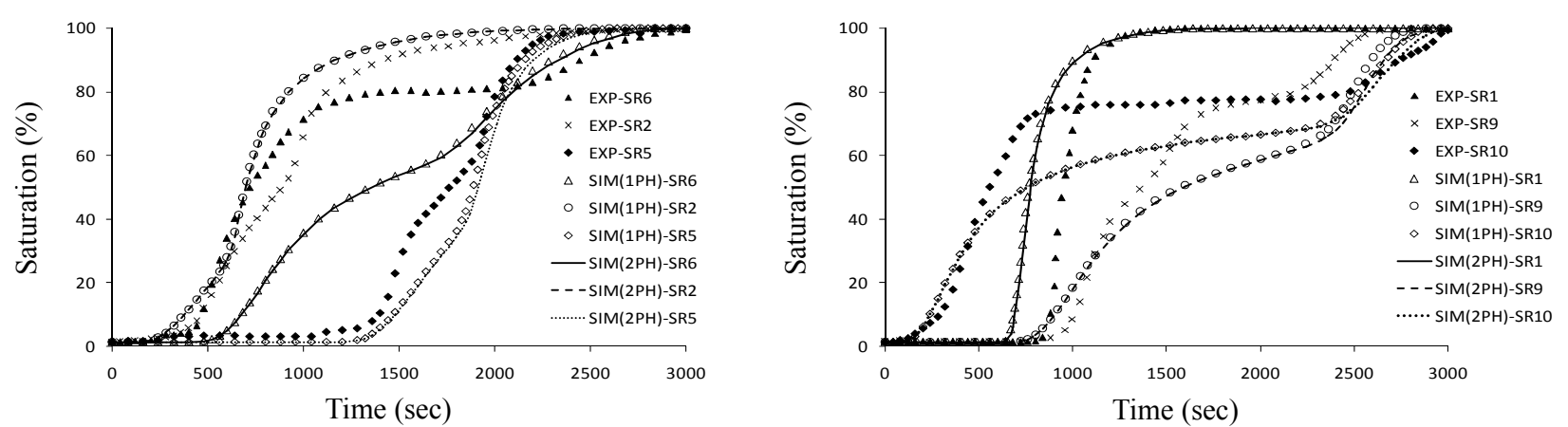

Fig. 6 Simulated and experimental moisture content profiles ( $28^{\circ}$ flume slope)

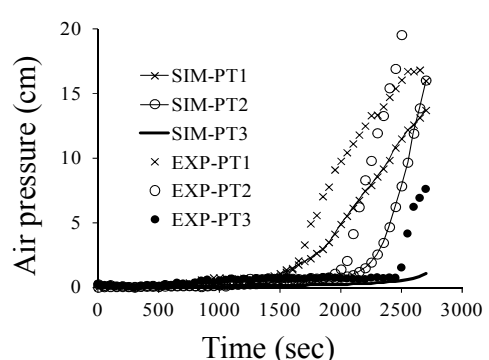

Fig. 7 Simulated and experimental air-pressure-head profiles

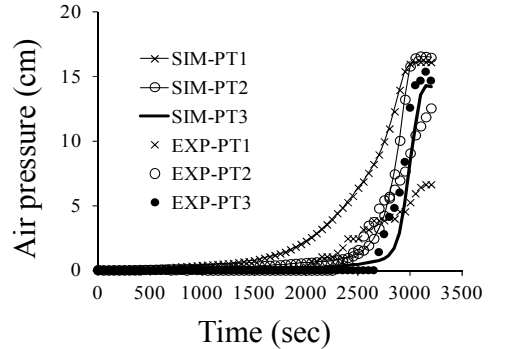

Time (sec)

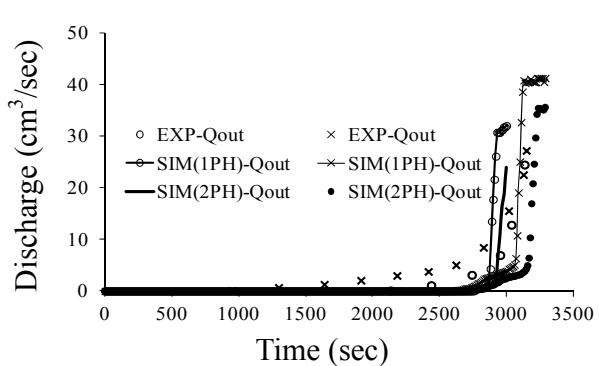

Fig. 8 Seepage outflow 


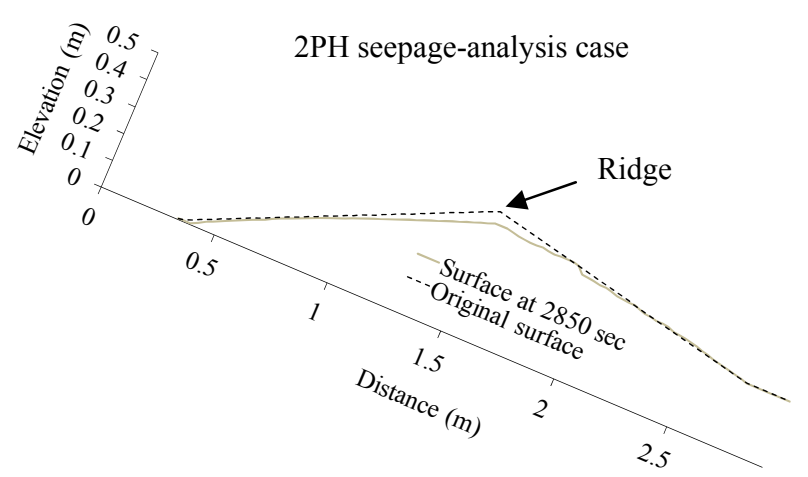

Fig. 9 Original and simulated soil surfaces at a longitudinal section through the center line $\left(23^{\circ}\right.$ flume slope $)$

Table 2 Surface-water forefront propagation time to measuring scales

\begin{tabular}{|c|c|c|c|c|}
\hline Scale & $\begin{array}{l}\text { Distance } \\
\text { parallel } \\
\text { to flume } \\
\text { slope } \\
\text { (m) }\end{array}$ & $\begin{array}{l}\text { Water } \\
\text { forefront } \\
\text { reached } \\
\text { time }(\mathrm{sec}) \\
\text { EXP }\end{array}$ & $\begin{array}{c}\text { Water } \\
\text { forefront } \\
\text { reached } \\
\text { time }(\mathrm{sec}) \\
\text { SIM-1PH }\end{array}$ & $\begin{array}{c}\text { Water } \\
\text { forefront } \\
\text { reached } \\
\text { time }(\mathrm{sec}) \\
\text { SIM-2PH }\end{array}$ \\
\hline \multicolumn{5}{|c|}{$23^{\circ}$ flume slope } \\
\hline 1 & 2.5 & 35 & 28 & 28 \\
\hline 2 & 2.3 & 77 & 111 & 113 \\
\hline 3 & 2.1 & 276 & 374 & 359 \\
\hline 4 & 1.9 & 761 & 975 & 951 \\
\hline 5 & 1.7 & 1369 & 1587 & 1527 \\
\hline 6 & 1.5 & 1983 & 2192 & 2138 \\
\hline \multicolumn{5}{|c|}{$28^{\circ}$ flume slope } \\
\hline 1 & 2.6 & 102 & 94 & 92 \\
\hline 2 & 2.45 & 497 & 436 & 422 \\
\hline 3 & 2.3 & 2153 & 1832 & 1646 \\
\hline 4 & 2.15 & 3184 & 2788 & 2788 \\
\hline
\end{tabular}

Table 3 Summary of slope-stability analysis

\begin{tabular}{|c|c|c|c|c|c|}
\hline \multicolumn{5}{|c|}{ Simulation } & \multirow[t]{3}{*}{ Experiment } \\
\hline \multirow{3}{*}{ 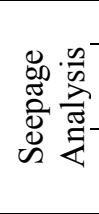 } & \multicolumn{4}{|c|}{ Slope-stability analysis method } & \\
\hline & \multicolumn{2}{|c|}{$\begin{array}{c}\text { Janbu's } \\
\text { simplified }\end{array}$} & \multicolumn{2}{|c|}{$\begin{array}{l}\text { Extended } \\
\text { Spencer }\end{array}$} & \\
\hline & $\begin{array}{c}\text { Failure } \\
\text { time }(\mathrm{sec})\end{array}$ & $\mathrm{F}_{\mathrm{s}}$ & $\begin{array}{l}\text { Failu } \\
\text { time }(\mathrm{s}\end{array}$ & c) $F_{s}$ & $\begin{array}{l}\text { Failure time } \\
\quad(\mathrm{sec})\end{array}$ \\
\hline \multicolumn{6}{|c|}{$23^{\circ}$ flume slope } \\
\hline $1-\mathrm{PH}$ & 2780 & 0.996 & 2820 & 0.984 & 2779 (EXP-D) \\
\hline 2-PH & 2830 & 0.992 & 2850 & 1.000 & 2830 (EXP-E) \\
\hline \multicolumn{6}{|c|}{$28^{\circ}$ flume slope } \\
\hline $1-\mathrm{PH}$ & 3020 & 0.994 & 3060 & 0.948 & \\
\hline 2-PH & 3100 & 0.979 & 3140 & 0.964 & 3286 \\
\hline
\end{tabular}

average simulated rainfall. Because PT3 was located near the downstream end of the model slope and surface water did not propagate into this reach, the simulation air-pressure-head profile in this position was influenced only by the localized rainfall intensity above it. This localized rainfall intensity in

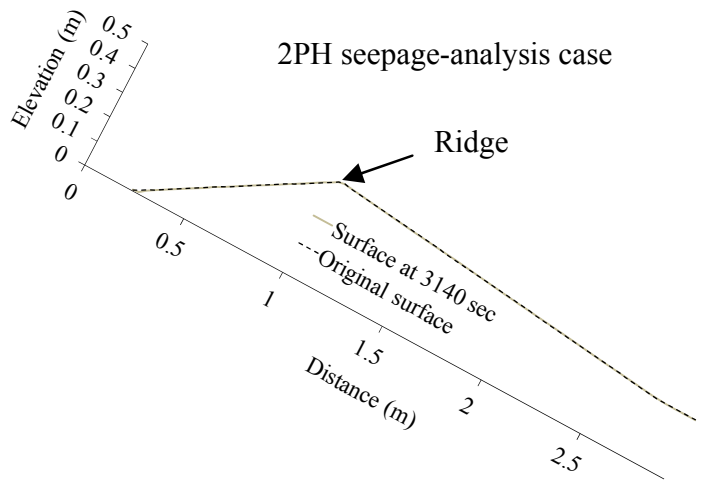

Fig. 10 Original and simulated soil surfaces at a longitudinal section through the center line ( $28^{\circ}$ flume slope)

the simulations might have been less than the actual value.

The $23^{\circ}$ flume-slope experiments were conducted in winter, whereas the $28^{\circ}$ flume-slope experiments were conducted in summer. Due to the seasonal temperature variation, the rainfall intensity provided by the rainfall simulator was higher than the average simulated rainfall value in the former case, whereas it was less than the average simulated value in the latter. Furthermore, the failure times of the model slopes were, on average, delayed in simulations compared with the experiments for the $23^{\circ}$ flume slope and accelerated in the simulations compared with the experiments for the $28^{\circ}$ flume slope (Table 3). Due to the reduction in the water-infiltration rate caused by the air phase, the surface-water forefront propagation in a two-phase simulation should be faster than that in a one-phase simulation. However, in some stages of the surface-water forefront, the degree of soil saturation just below the forefront is reduced due to a delay in the lateral movement of seepage water from upstream. In such stages, the infiltration rate from the surface is higher, so the propagation rate can be delayed substantially. At measuring scale 2 for the $23^{\circ}$ flume slope (Table 2), the surface-water propagation time was delayed somewhat in the two-phase flow compared with the one-phase flow. At measuring scale 4 for the $28^{\circ}$ flume slope (Table 2), the surface-water propagation time was the same in the two-phase and one-phase simulations. At the other scale positions, the surface-water propagation time was faster in the two-phase flow than in the one-phase flow.

Figs. 9 and 10 compare the soil-surface profiles obtained from the simulations at the time of failure in the model slopes, considering the two-phase seepage-flow analysis, with the original soil surface at the longitudinal section through the center line. In the $23^{\circ}$ flume slope, the area upstream from the 
model slope was comparatively larger than that for the $28^{\circ}$ flume slope (Figs. 1 and 2). The runoff input of the model slope for the former was greater than that for the latter. Due to the smaller flume slope, the vertical distance traveled by the infiltrating water from the soil surface to the bottom impervious layer was less in the former than the latter, so the particular depth was saturated earlier in the former. Therefore, the surface-water flow was faster in the $23^{\circ}$ flume slope than in the $28^{\circ}$ flume slope; it crossed the ridgeline before the failure of the model slope, and significant erosion occurred in the simulations (Fig. 9). By contrast, in the $28^{\circ}$ flume slope, the surface water flow did not cross the ridgeline before the failure, and no erosion was observed in the simulations (Fig. 10).

The time of failure of the model slope and the corresponding safety factor calculated by different methods in different cases are summarized in Table 3. Figs. 11 and $\mathbf{1 2}$ show the failure surfaces obtained from the simulations and experiments in longitudinal profile. Fig. 13 presents a 3D view of the failure surface observed in experiment $D$ and computed using the extended Spencer method considering two-phase flow for the $23^{\circ}$ flume slope. Similarly, Fig. 14 presents a 3D view of the failure surface observed in an experiment and computed with the extended Spencer method considering two-phase flow for the $28^{\circ}$ flume slope. The comparison indicated that the simulated and experimental failure surfaces, as well as the corresponding times of failure, matched well. The failure time of the numerical analysis corresponded to the time at which the computed $F_{s} \leq 1.0$. Although a slope-stability simulation is possible for each time step of the seepage analysis, 10 -sec time steps were used to reduce the simulation duration. Therefore, the $F_{s}$ values in the different simulations were not the same. In the experiment, the moment of failure of the model slope was judged from the recorded video clips.

Because the overall rainfall intensity was more intense on side A than on side B (Fig. 4), the observed sliding slope with a deeper failure surface was concentrated on side $\mathrm{A}$ in the experiments as well as the simulations. Nearer side B, the failure surface predicted by the simulation was shallower than that observed experimentally in both cases. However, the failure plane in the simulation was not observed at side B in the $28^{\circ}$ flume slope (Fig. 14). These phenomena are explained by the unreliable rainfall supply, mentioned above. There must be some deposition in the toe of the model slope after failure. However, to predict the deposition, a model must be developed to determine the distance moved by the failure mass and its shape and size after movement. Therefore, Figs. 13 and 14 present only the failure surface in the original shape of the model slope.

Worldwide, slopes exist in residual soil deposits. These soils are often unsaturated, and the conventional approach that assumes only water-phase flow in seepage analysis is inadequate. To improve seepage analyses, a water-air two-phase flow model has been used to consider the air movement phenomenon inside the body of the model slope. The simulated moisture profiles from the water-air two-phase seepage-flow models occurred
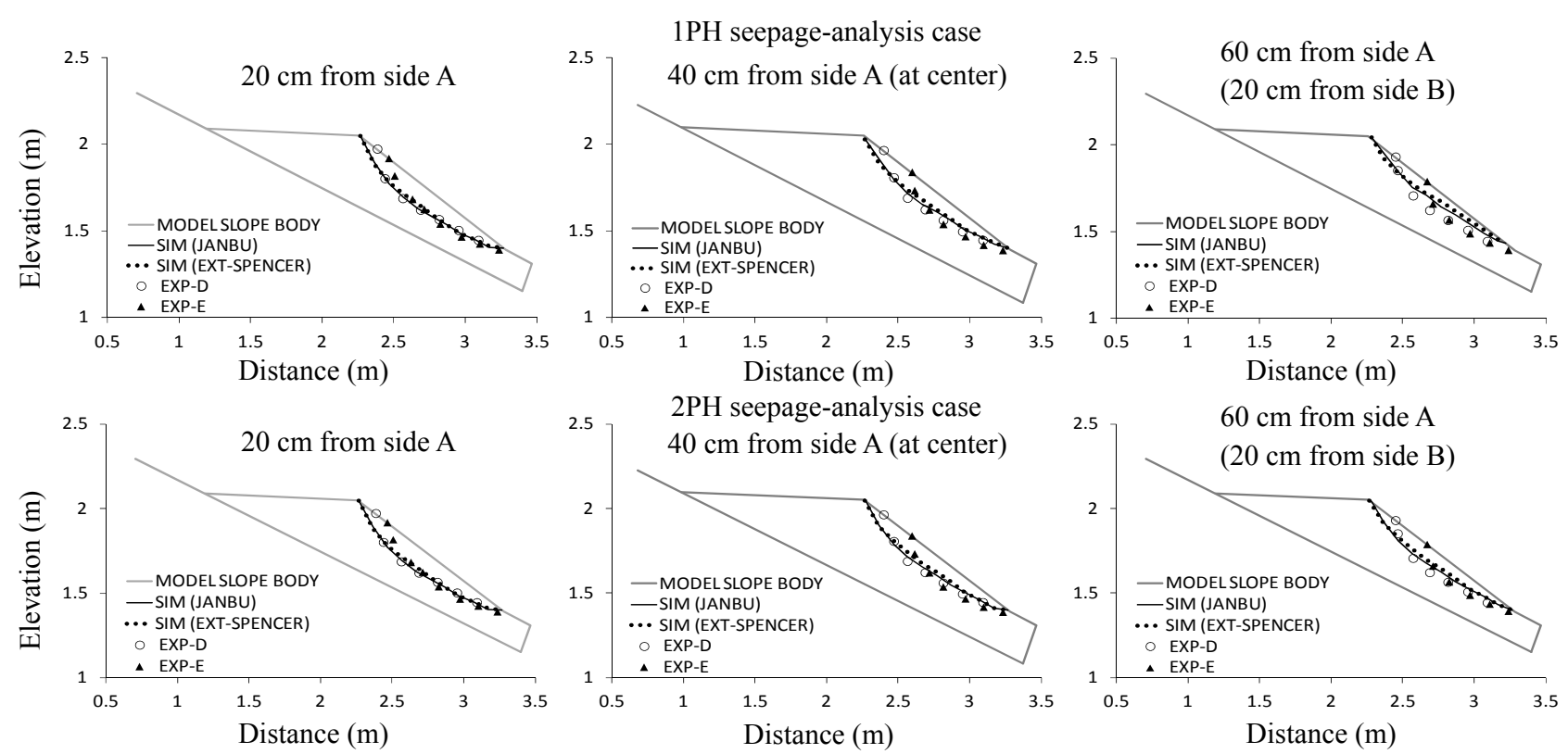

Fig. 11 Comparison of the longitudinal profiles of the experimental and simulated failure surfaces $\left(23^{\circ}\right.$ flume slope) 

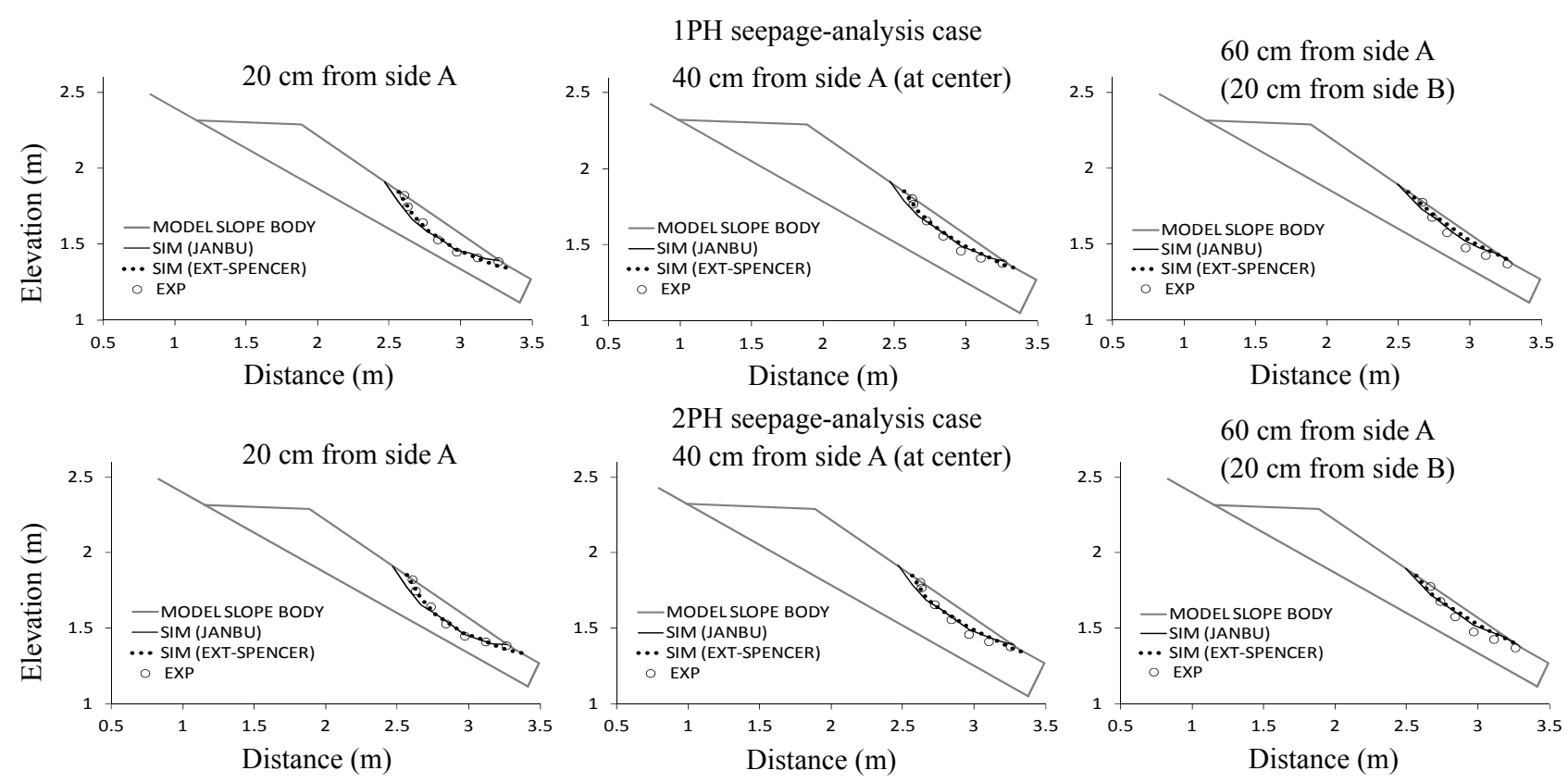

Fig. 12 Comparison of the longitudinal profiles of the experimental and simulated failure surfaces ( $28^{\circ}$ flume slope)
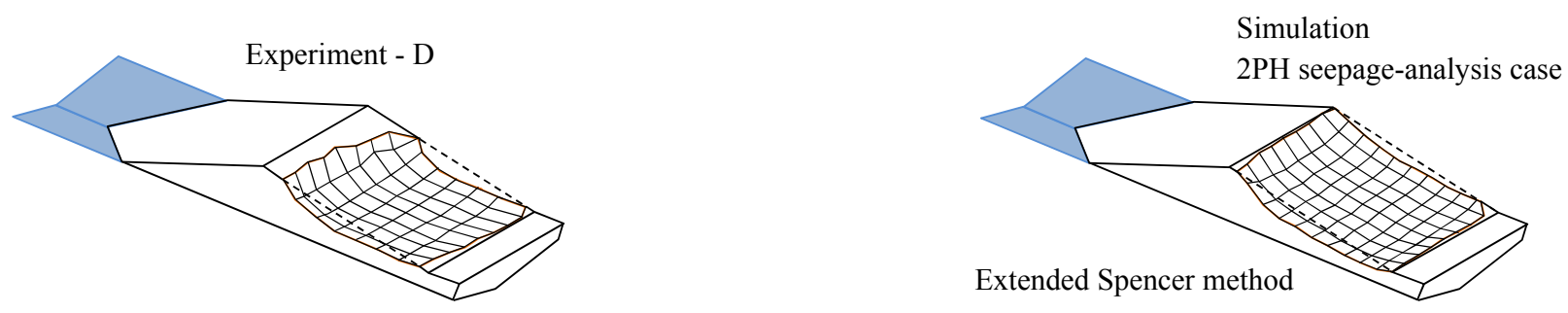

Fig. $133 \mathrm{D}$ view of failure surface $\left(23^{\circ}\right.$ flume slope $)$
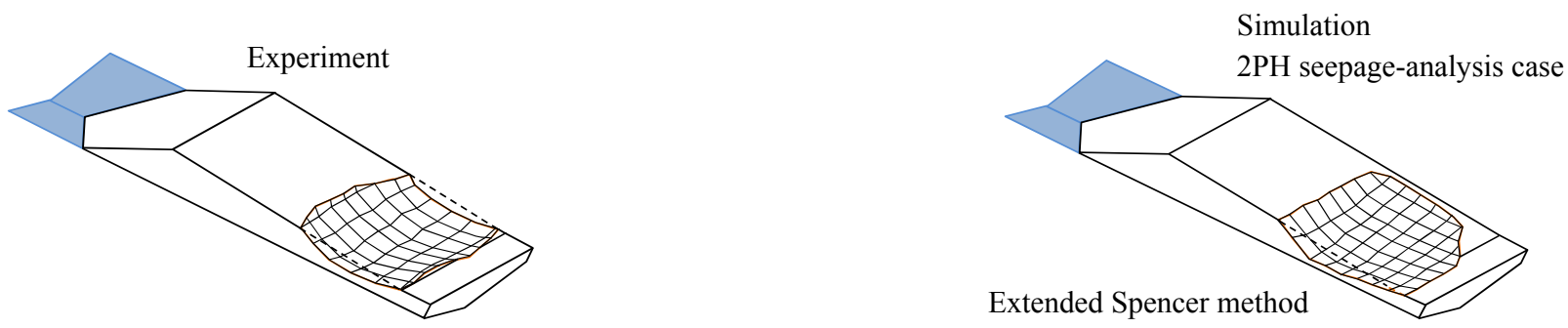

Fig. $143 \mathrm{D}$ view of failure surface $\left(28^{\circ}\right.$ flume slope $)$

slightly after those of the conventional seepage-flow models (Fig. 5 and Fig. 6). Ultimately, the failure time of the slope body was delayed using Janbu's simplified method and the extended Spencer method (Table 3). However, only for the $28^{\circ}$ flume slope, the failure times from the two-phase flow model were closer to the values observed experimentally compared with those from the one-phase flow model. To improve this modeling approach, additional experimental verifications in different soils and field applications are necessary.

Janbu's simplified method satisfies only the force equilibrium for the entire sliding mass and assumes that the resultant interslice forces are horizontal, whereas the extended Spencer method satisfies both the force and moment equilibria and assumes that the resultant interslice forces are at an angle to the horizontal. Due to the vertical component of inclined interslice forces, the calculated mobilized shear stress using the extended Spencer method is less than that of Janbu's simplified method at a given moisture content. Therefore, the safety factor calculated using Janbu's simplified method was less than that from the extended Spencer method, resulting in a delayed failure time for the body of the model slope compared with Janbu's simplified method.

\section{CONCLUSIONS}


This study conducted a slope-stability analysis using the pore-water pressure and moisture content calculated by a 3D seepage-flow model. Both a conventional water-phase flow model and water-air two-phase seepage-flow model, coupled with a 2D surface flow and erosion/deposition model, were used for the seepage analysis. The numerical simulation results and experimental measurements are in satisfactory agreement in terms of moisture movement, air movement, seepage-outflow rate, surface-water forefront propagation, predicted critical slip surfaces, and time of failure of the considered model slope. The simulated moisture profiles from the water-air two-phase seepage-flow model were delayed slightly compared with those from the one-phase seepage-flow model. Additionally, the simulated failure time of the model slope was delayed when using the extended Spencer method for slope-stability analysis compared with Janbu's simplified method of slope-stability analysis. Additional experimental studies are necessary to obtain experimental and simulated results that are in better agreement.

ACKNOWLEDGMENT: The financial support provided by the Japan Society for the Promotion of Science (JSPS) Grant-in-Aid for Scientific Research (B) 22360197 (Hajime Nakagawa, Kyoto University) to this research is gratefully acknowledged.

\section{REFERENCES}

Awal, R., Nakagawa, H., Kawaike, K., Baba, Y. and Zhang, H. (2009): Three dimensional transient seepage and slope stability analysis of landslide dam, Annuals of Disaster Prevention Research Institute, Kyoto University, No. 52B, pp. 689-696.

Chen, J., Hopmans, J. W. and Grismer, M. E. (1999): Parameter estimation of two-fluid capillary pressure-saturation and permeability functions, Advances in Water Resources, Vol. 22, No.5, pp.479-493.

Crozier, M. J. (1999): Prediction of rainfall-triggered landslides: a test of the Antecedent Water Status Model, Earth Surface Processes and Landforms, Vol. 24, pp. 825-833.

Dakshanamurthy, V., Fredlund, D.G. and Rahardjo, H. (1984): Coupled three-dimensional consolidation theory of unsaturated porous media, Proceedings of the Fifth International Conference on Expansive Soils, Adelaide, South Australia.

Fredlund, D.G., Morgenstern, N.R. and Widger, R.A. (1978): The shear strength of unsaturated soils, Canadian Geotechnical Journal, Vol. 15, pp. 313-321.

Freeze, R. A. (1978): Mathematical models of hillslope hydrology, in Kirkby, M. J., ed., Hillslope Hydrology, John Wiley, pp. 177-225.

Fukuzono, T. (1987): Experimental study of slope failure caused by heavy rainfall, Erosion and Sedimentation in the Pacific Rim, Proceedings of the Corvallis Symposium, August.

Jiang, J.C. and Yamagami, T. (2004): Three-dimensional slope stability analysis using an extended Spencer method, Soils and Foundations, Japanese Geotechnical Society, Vol. 44, No. 4, pp. 127-135.

Leong, E.C. and Rahardjo, H. (1997): Review of soil-water characteristic curve equations, Journal of Geotechnical and Geo-environmental Engineering, Vol. 123, No.12, pp.1106-1117.

Mukhlisin, M. and Taha, M.R. (2009): Slope stability analysis of a weathered granitic hillslope as effects of soil thickness, European Journal of Scientific Research, Vol. 30, No. 1, pp. 36-44.

Nakagawa, H. (1989): Study on risk evaluation of flood and sediment inundation disaster, Doctoral Thesis, Kyoto University (in Japanese).

Nakagawa, H., Takahashi, T., Satofuka, Y. and Kawaike, K. (2003): Numerical simulation of sediment disasters caused by heavy rainfall in Camuri Grande basin, Venezuela 1999, Proceedings of the Third Conference on Debris-Flow Hazards Mitigation: Mechanics, Prediction, and Assessment, Switzerland, Rotterdam, pp. 671-682.

Sassa, K. (1972): Analysis on slope stability: I, Mainly on the basis of the indoor experiments using the standard sand produced in Toyoura, Japan, Journal of the Japan Society of Erosion Control Engineering, Vol. 25, No. 2, pp. 5-17 (in Japanese with English abstract).

Sassa, K. (1974): Analysis on slope stability: II, Mainly on the basis of the indoor experiments using the standard sand produced in Toyoura, Japan, Journal of the Japan Society of Erosion Control Engineering, Vol. 26, No. 3, pp. 8-19 (in Japanese with English abstract).

Takahashi T. (1991): Debris flow, Monograph Series of IAHR, Balkema, pp. 1-165.

Takahashi, T. and Nakagawa, H. (1994): Flood/debris flow hydrograph due to collapse of natural dam by overtopping, Journal of Hydroscience and Hydraulic Engineering, JSCE, Vol. 12, No. 2, pp. 41-49.

Touma, J. and Vauclin, M. (1986): Experimental and numerical analysis of two-phase infiltration in a partially saturated soil, Transport in Porous Media, Vol. 1, pp. 27-55.

Tsai, T.L., Chen, H.E. and Yang, J.C. (2008): Numerical modeling of rainstorm-induced shallow landslides in saturated and unsaturated soils, Environmental Geology, Vol. 55, pp. 1269-1277.

Tsutsumi, D. and Fujita, M. (2008): Relative importance of slope material properties and timing of rain fall for the occurrence of landslides, International Journal of Erosion Control Engineering, Vol. 1, No. 2.

van Genuchten, M. T. (1980): A closed-form equation for predicting the hydraulic conductivity of unsaturated soils, Soil Science Society of America Journal, Vol. 44, No. 5, pp. 892-898.

Received: 22 August, 2011

Accepted: 7 May, 2012 